\title{
Analisis Hubungan Perilaku Pemeliharaan Kesehatan Gigi dan Mulut Terhadap Status Kesehatan Gigi dan Mulut Siswa SD dan SMP di Medan
}

\author{
Sondang Pintauli \\ Departemen IImu Kedokteran Gigi Pencegahan/Kesehatan Gigi Masyarakat \\ Fakultas Kedokteran Gigi USU Medan, email: sondangp@yahoo.com
}

\begin{abstract}
Abstrak: Penelitian ini bertujuan untuk mengetahui hubungan perilaku pemeliharaan kesehatan gigi dan mulut terhadap status kesehatan gigi dan mulut siswa kelas VI SD dan III SMP di Kota Medan. Total sampel 393 orang yang diambil secara stratifikasi-klaster 2 tingkat, di mana siswa SD 197 orang dan SMP 196 orang. Pengambilan data dilakukan dengan wawancara dan observasi, serta uji statistik menggunakan one-way ANOVA. Hasil penelitian menunjukkan bahwa: 1) prevalensi karies siswa SD 92,39\% dengan DMFT 3,42 22,36 dan meningkat pada siswa SMP menjadi 93,37\% dengan DMFT 3,79 $\pm 2,69$. Siswa SMP mempunyai $>3$ sekstan sehat sesuai dengan target pencapaian gigi sehat WHO. Skor OHIS sebagian besar siswa SD dan SMP (50,8 dan 52,6\%) pada kategori sedang; 2 ) 61,4\% siswa SD mempunyai perilaku pemeliharaan kesehatan gigi yang baik, sedangkan pada siswa SMP hanya 30,1\%;3) terdapat hubungan yang signifikan antara perilaku pemeliharaan kesehatan gigi dengan skor pengalaman karies (DMFT) dan skor kebersihan mulut (OHIS) $(p<0,05)$, sebaliknya tidak dijumpai hubungan yang signifikan antara perilaku pemeliharaan kesehatan gigi dengan status periodontal $(p>0,05)$.
\end{abstract}

Kata kunci: kesehatan gigi, perilaku kesehatan, DMFT, status periodontal, dan skor oral higiene

\begin{abstract}
The purpose of this study was to analyze the relationship between oral health status (caries and periodontal status, oral hygiene) and oral health behavior of sixth grade primary and third grade of junior high school students in Medan. 393 children (197 primary school students and 196 junior high school students) were selected at cluster stratification. Dental caries and periodontal status of students was evaluated using the World Health Organization (WHO) diagnostic criteria. The oral hygiene of each child was assessed using the scoring of Simplified Oral Hygiene Index (OHI-S) from Greene and Vermillion. Interviews were conducted using a questionnaire to determine the oral health behavior of the children. The results showed that: 1 ) the caries prevalence of primary school children $92,39 \%$ with mean DMFT $3,42 \pm 2,36$, and found higher in junior high school students $93,37 \%$ with mean DMFT $3,79 \pm 2,69$. Junior high school students have $>3$ health sextants according to WHO. Almost all of students in both groups $(50.8$ and $52.6 \%)$ in moderate category; 2 ) $61.4 \%$ of the primary school students with good oral health habits while in junior high school students only $30.1 \%$; 3 ) no statistically differences between oral health behavior and periodontal status ( $p>0.05$ ), it was found significant differences between oral health behavior and caries experience and also oral hygiene $(p<0.05)$.
\end{abstract}

Key words: oral health, health behaviour, DMFT, periodontal status, and oral hygiene

\section{Pendahuluan}

Kesehatan gigi dan mulut merupakan bagian integral dari kesehatan tubuh, artinya tubuh yang sehat tidak terlepas dari memiliki gigi dan mulut yang sehat. Oleh karena itu, untuk melaksanakan pembangunan di bidang kesehatan, pembangunan di bidang kesehatan gigi tidak boleh ditinggalkan. Namun, saat ini kesadaran masyarakat Indonesia akan pentingnya memiliki kualitas gigi dan mulut yang sehat masih kurang. Hal ini terbukti dengan adanya lebih dari setengah populasi umur 10 tahun ke atas di Indonesia mengalami masalah gigi berlubang yang belum ditangani. Gigi berlubang atau disebut karies ditandai dengan kerusakan struktur gigi sehingga menyebabkan terbentuknya lubang pada gigi. Apabila tidak ditangani segera, penyakit ini lama kelamaan dapat menimbulkan nyeri, rasa sakit, 
dan kehilangan gigi bahkan menjadi pemicu timbulnya berbagai penyakit berbahaya. Beberapa studi melaporkan adanya hubungan antara penyakit gigi dengan penyakit jantung koroner, aterosklerosis, pneumonia, diabetes dan kelahiran prematur (Axellson, 1999; Peterson, 2003).

Selain karies, penyakit gusi (gingivitis) juga merupakan masalah gigi dan mulut yang banyak dialami oleh anak-anak di negara berkembang termasuk di Indonesia, dan prevalensinya cenderung meningkat pada setiap dasawarsa. Berbagai penelitian kesehatan gigi dan mulut menunjukkan tingginya prevalensi karies dan gingivitis pada anak-anak. Hasil Riset Kesehatan Dasar tahun 2007 (DepKes, 2008) melaporkan bahwa prevalensi karies aktif pada usia 12 tahun sebesar 29,8\% dengan indeks pengalaman karies (DMFT) 0,91 dan mencapai 4,46 pada usia 35-44 tahun. Hasil penelitian yang dilakukan oleh Octiara (2001) pada anak usia 6-14 tahun yang tinggal di Panti Karya Pungal, Binjai, Sumatera Utara menunjukkan bahwa prevalensi karies 64,59\% dengan rerata DMFT 1,6 dan skor kebersihan mulut (OHI) 2,37 yang termasuk criteria sedang (Octiara, 2001). Tanpa disadari, penyakit gigi pada anak akan berdampak terhadap produktivitas si anak. Keluhan sakit gigi dapat mengakibatkan si anak tidak pergi ke sekolah dengan rerata lama terganggu 3,86 hari. Apa yang diuraikan sebelumnya mencerminkan minimnya derajat kesehatan gigi dan mulut anak Indonesia. Kondisi ini juga akan berpengaruh terhadap derajat kesehatan anak, proses tumbuh kembang anak bahkan hilangnya masa depan mereka (Irmawati \& Satiti, 2001, DepKes RI, 2000). Anak-anak rawan kekurangan gizi karena rasa sakit pada gigi dan mulut dapat menurunkan selera makan mereka. Dampak lainnya, kemampuan belajar mereka juga menurun sehingga akan berpengaruh pada tingkat kecerdasan dan prestasi belajarnya (Astoeti, 2006).

Hasil penelitian di Kota Medan menunjukkan prevalensi penyakit gigi dan mulut yang cukup tinggi untuk anak sekolah. Hal ini dapat dilihat dari Profil Data Dinas Kesehatan Kota Medan tahun 2007 di beberapa Puskesmas Lingkar Dalam dan Puskemas Lingkar Luar Kota Medan yang menunjukkan prevalensi karies gigi untuk anak usia sekolah di Kota Medan sebanyak 74,69\%.
Data ini menjadi bukti bahwa kegiatan Upaya Kesehatan Gigi Sekolah (UKGS) di sekolah belum dapat meminimalkan masalah kesehatan gigi di Indonesia dan menunjukkan bahwa cakupan pelayanan kesehatan gigi masih belum tercapai.

Organisasi Kesehatan Dunia (WHO) telah menetapkan Oral Health Global Indicators for year 2025, yang salah satunya adalah skor DMFT anak usia 12 tahun tidak boleh lebih dari 1 (Axelsson, 1999). Ketetapan ini dianut oleh Departemen Kesehatan yang telah membuat indikator kesehatan gigi dan mulut dengan melihat status kesehatan gigi anak usia 12 tahun yang disesuaikan dengan target pada tahun 2010 yaitu rerata $\mathrm{DMF}=1$, prevalensi karies gigi kurang dari $50 \%$ dan nilai Indeks Performed Treatment $(\mathrm{PTI})=$ $50 \%$ (Depkes RI, 2000). Hal yang diuraikan sebelumnya menunjukkan pentingnya upaya pencegahan dan perawatan kesehatan gigi dan mulut untuk menurunkan prevalensi karies dan terhindar dari komplikasi penyakit gigi yang membahayakan.

Salah satu cara yang dapat dilakukan adalah memfokuskan jangkauan pelayanan pencegahan untuk program di sekolah (school-based dental health program) seperti Upaya Kesehatan Gigi Sekolah (UKGS) dengan menanamkan pentingnya perilaku sehat sejak anak duduk di bangku SD hingga ia menyelesaikan pendidikan di tingkat SMA. Upaya pencegahan yang paling efektif adalah yang dilakukan oleh siswa di sekolah karena perilaku hidup sehat harus ditekankan sejak dini dan dilakukan secara terus menerus agar menjadi kebiasaan (Debnath, 2002; DepKes RI, 2004). Di samping itu, kelompok ini juga lebih mudah dibentuk mengingat anak sekolah selalu di bimbing dan diawasi para guru sehingga sangat potensial bila ditanamkan kebiasaan berperilaku hidup sehat. Dalam Undang-Undang Nomor 23 Tahun 1992 tentang Kesehatan disebutkan bahwa penyelenggaraan kesehatan sekolah ditujukan untuk meningkatkan kemampuan hidup sehat bagi peserta didik sehingga mereka dapat belajar, tumbuh dan berkembang secara harmonis dan optimal menjadi sumber daya manusia yang lebih berkualitas. Salah satu keuntungan sekolah berbasis program kesehatan adalah memberi kesempatan untuk menjangkau lebih banyak anak selama masa awal perkembangan yaitu 
pada saat pola kesehatan masih dapat dirubah atau dimodifikasi. Keadaan sekolah juga memberikan suasana yang mendukung untuk belajar (learning) dan memacu (reinforcement) anak sehingga guru dapat menggunakan strategi/ metode baru untuk mengajak anak-anak berpartisipasi dalam tindakan pencegahan penyakit gigi dan mulut (Debnath, 2002). Pemeliharaan gigi siswa secara umum terkait dengan peran stakeholders atau orang-orang yang relatif dekat dengan siswa yang terkait dengan masalah kesehatan gigi seperti: 1) keluarga siswa terutama orangtua/ibu; 2) guru khususnya guru Olah Raga dan Kesehatan melalui pendidikan kesehatan di sekolah; dan 3) tenaga kesehatan gigi di puskesmas. Sayangnya, sekolah atau keluarga belum memberikan dukungan optimal terhadap upaya menjaga kesehatan gigi dan mulut anak (Debnath, 2002).

Salah satu kebijakan yang diambil oleh Dinas Kesehatan Kota Medan untuk tahun 2007-2010 adalah peningkatan partisipasi seluruh lapisan masyarakat termasuk siswa sekolah pendidikan dasar dan menengah dalam rangka meningkatkan kesadaran, kemampuan dan membentuk perilaku hidup sehat serta ikut dalam upaya pencegahan penyakit dan peningkatan derajat kesehatan (Dinas Kesehatan Kota Medan, 2008). Berdasarkan apa yang diuraikan dalam latar belakang masalah, maka rumusan penelitian ini adalah: "Apakah ada hubungan antara perilaku dan status kesehatan gigi dan mulut siswa SD dan SMP di Kota Medan?'

Penelitian ini bertujuan untuk mengetahui: 1) gambaran status kesehatan gigi dan mulut murid SD dan SMP di Kota Medan; 2) gambaran perilaku pemeliharaan kesehatan gigi dan mulut siswa SD dan SMP di Kota Medan; dan 3) hubungan perilaku dan status kesehatan gigi dan mulut siswa SD dan SMP di Kota Medan

\section{Kajian Literatur}

Gigi dan mulut mempunyai arti penting dalam kehidupan manusia. Walaupun demikian, masih banyak orang yang tidak tahu bahwa rongga mulut adalah organ yang berperan penting bagi kesehatan tubuh. Rongga mulut dikatakan sehat tidak hanya bila mempunyai susunan gigi yang cantik, rapi dan teratur saja tetapi juga harus bebas dari bau mulut, rasa sakit oro-fasial kronis, kanker, lesi oral dan penyakit atau gangguan lain yang melibatkan gigi, mulut dan sistem stomatognasi. Selain berfungsi untuk berkomunikasi secara efektif, rongga mulut yang sehat memungkinkan seseorang menikmati berbagai jenis makanan dan meningkatkan kualitas hidupnya. Hasil penelitian menunjukkan bahwa status kesehatan gigi dan mulut akan mempengaruhi kualitas hidup seseorang dalam domain yang saling berkaitan, meliputi gejala rasa sakit di rongga mulut, fungsi fisik, psikis dan fungsi sosialnya. Oleh karena itu, kesehatan gigi dan mulut sangat berperan dalam menunjang kesehatan seseorang (Pintauli \& Hamada, 2007).

Dalam Iaporan Survei Kesehatan Rumah Tangga dinyatakan bahwa penyakit gigi dan mulut merupakan penyakit tertinggi keenam yang dikeluhkan masyarakat Indonesia (DepKes RI, 2004) dan menempati peringkat keempat penyakit termahal dalam pengobatan (WHO, 2003). Seperti telah digariskan oleh WHO, sehat dapat diartikan sebagai keadaan yang bebas dari segala macam penyakit, dan bukan hanya bebas dari penyakit, melainkan juga sejahtera secara psikis dan sosial (WHO, 1997). Agar dapat mencapai kesejahteraan hidup yang optimal harus ada keseimbangan antara kesehatan fisik dan kesehatan mental, sehingga antara individu dan lingkungannya dapat terjalin hubungan yang serasi dan selaras.

\section{Status Kesehatan Gigi dan Mulut}

Status kesehatan gigi dan mulut dapat digambarkan dengan indikator sebagai berikut (WHO, 1997): 1) Indeks pengalaman karies (DMFT) merupakan indikator keadaan gigi yang mengalami kerusakan, hilang atau ditambal akibat adanya karies; 2) Indeks penyakit periodontal merupakan indeks CPITN (WHO) untuk mengukur kondisi jaringan periodontal serta perkiraan kebutuhan perawatannya; 3) Indeks kebersihan mulut yang merupakan indikator untuk melihat kebersihan mulut dengan melihat ada tidaknya debris dan kalkulus dengan indeks OHIS.

Profil Kesehatan Gigi di Indonesia menunjukkan bahwa skor DMFT pada kelompok anak usia 12 tahun adalah 2,69. Prevalensi penyakit periodontal di Indonesia, berdasarkan penelitian 
yang dilaksanakan oleh Direktorat Kesehatan Gigi Departemen Kesehatan Republik Indonesia diperoleh angka $60 \%$ untuk anak usia 8 tahun dan $90 \%$ untuk anak usia 14 tahun. Selain itu, dilaporkan untuk penduduk usia 10 tahun ke atas, $46 \%$ mengalami penyakit periodontal, dan prevalensi ini semakin tinggi pada umur yang lebih tinggi (DepKes RI, 2004). Kondisi ini dihubungkan dengan perilaku terhadap kesehatan gigi yang kurang baik.

Dewasa ini kesadaran para siswa terhadap pentingnya arti kesehatan gigi masih kurang. Pengetahuan atau kognitif merupakan ranah yang sangat penting untuk terbentuknya tindakan seseorang. Pengetahuan tentang kesehatan gigi dan mulut akan mendasari sikap yang mempengaruhi tindakan dan membentuk suatu perilaku seseorang dalam memelihara kebersihan mulutnya sehingga siswa tidak hanya sehat tubuhnya tetapi juga memiliki gigi dan mulut yang sehat.

\section{Perilaku Kesehatan}

Menurut Murphy (2004), faktor perilaku merupakan salah satu faktor yang dapat mempengaruhi status kesehatan seseorang. Mengubah perilaku manusia bukanlah usaha yang mudah. Hal ini disebabkan manusia merupakan individu yang mempunyai sikap, kepribadian dan latar belakang sosial ekonomi yang berbeda. Untuk itu, diperlukan kesungguhan dari berbagai komponen masyarakat untuk ikut andil dalam mengubah perilaku (Herijulianti dkk, 2001). Pernyataan ini mendukung apa yang telah diuraikan oleh Wright (1998) dalam kaitannya dengan status kesehatan gigi anak dengan terlibatnya 3 komponen yaitu anak, orangtua/guru dan tenaga kesehatan. Hubungan ini digambarkan dalam bentuk segitiga sama sisi yang disebut Paedodontic Treatment Angle.

\section{Peran orangtua}

Dalam hubungannya dengan perilaku kesehatan, maka anak-anak mempunyai hubungan yang dekat dengan orangtua terutama ibunya. Umumnya pemeliharaan kesehatan anak-anak bergantung pada ibunya. Kedekatan hubungan ibu dengan anaknya telah dikemukakan oleh Fukuta seperti yang dikutip Budiharto (1998) yang menyatakan bahwa perilaku ibu mengenai kesehatan gigi dapat digunakan untuk meramalkan status kesehatan gigi anaknya. Apabila perilaku ibu mengenai kesehatan gigi baik, dapat diramalkan bahwa status kesehatan gigi dan gusi anaknya juga baik. Oleh karena itu, dalam komite sekolah sudah seharusnya keterlibatan orangtua diperhitungkan sehingga perubahan perilaku dapat menjadi tanggung jawab ketiga komponen sumber daya termasuk tenaga keseahatan dan guru (Budiharto, 1998).

\section{Peran Guru}

Sekolah adalah lembaga formal yang di dalamnya terdapat kurikulum, guru, siswa, metode belajar, media belajar dan fasilitas yang diperlukan dalam melakukan kegiatan belajar. Untuk pelaksanaan program Upaya Kesehatan Gigi Sekolah (UKGS) khususnya, diharapkan keterlibatan sekolah dan kepala sekolah/guru. Sebagaimana diketahui bahwa selama ini UKGS hanya dilakukan oleh

anak

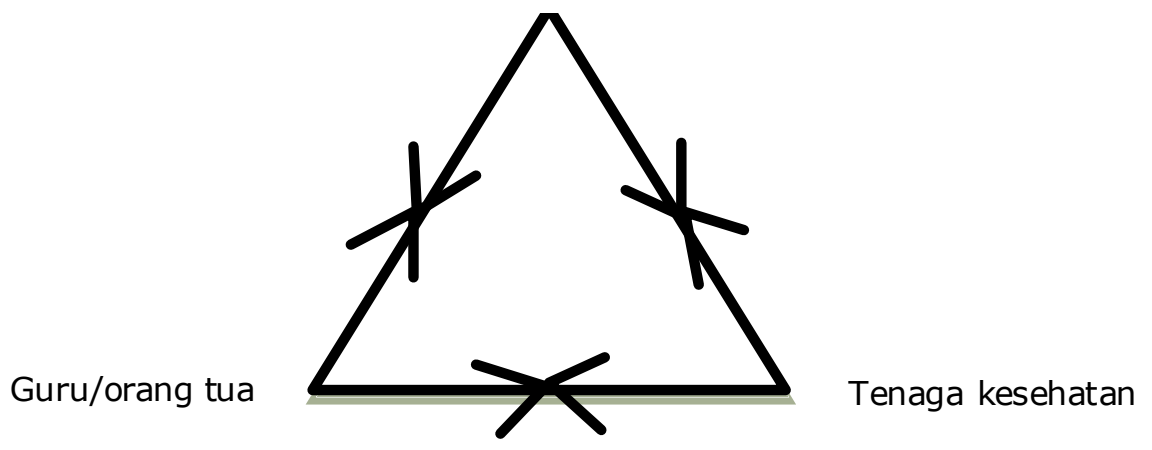

Gambar 1. Hubungan 3 komponen dalam status kesehatan gigi anak (Wright, 1998) 
guru bidang olah raga. Sementara itu, Kepala sekolah/guru merupakan tokoh yang disegani dan menjadi panutan di sekolah sehingga keterlibatannya dalam pelaksanaan UKGS sangat mempengaruhi kesediaan murid dan para orang tua murid dalam memelihara kesehatan gigi dan mulut di rumah, sekolah dan puskesmas (Astoeti, 2006; Herijulianti dkk, 2001).

Dalam proses belajar mengajar terjadi hubungan timbal balik antara guru dan siswa. Hubungan yang terjalin sebaiknya tidak kaku, guru dapat menempatkan diri secara tepat dan bijak, sehingga dapat mengetahui sampai sejauh mana pemahaman materi yang disampaikan serta dapat mengetahui kelemahan siswa sekaligus penyebabnya.

\section{Peran Tenaga Kesehatan}

Tenaga kesehatan yang dilibatkan dalam UKGS adalah dokter gigi dan perawat gigi. Peran tenaga kesehatan dalam pendidikan kesehatan gigi adalah dapat merubah perilaku masyarakat dari perilaku yang tidak sehat ke arah perilaku sehat. Dalam menjalankan perannya, tenaga kesehatan harus mampu menyadarkan masyarakat termasuk anak-anak tentang permasalahan yang terjadi dan memberi penjelasan mengenai sebab-sebab timbulnya masalah dan cara mengatasinya.

\section{Pencegahan Penyakit Gigi dan Mulut}

Sebenarnya kesadaran akan pentingnya kesehatan gigi dan mulut telah lama ada di kalangan kedokteran gigi. Hal ini terbukti dari timbulnya perubahan yang sangat mendasar dalam konsep perawatan kedokteran gigi sejak sekitar tahun 1970. Oleh karena itu, tidak heran bila sebelumnya banyak orang menganggap pencabutan gigi sebagai tindakan yang tepat untuk menghilangkan sakit gigi. Dilihat dari segi kebutuhan pasien pada saat adanya keluhan, pencabutan gigi merupakan tindakan yang sangat membantu, karena dengan hilangnya gigi yang sakit maka pasien terlepas dari penderitaannya. Namun demikian, jika dipandang dari segi kebutuhan fungsional, pencabutan gigi merupakan awal terjadinya rangkaian masalah baru. Kehilangan gigi akan mengurangi kenyamanan dan efisiensi mengunyah; oleh karena itu, belakangan ini perawatan lebih diarahkan kepada upaya perawatan atau pemeliharaan kestabilan fungsi seluruh sistem pengunyahan, baik melalui tindakan pencegahan ataupun pemulihan.

Beberapa tindakan pencegahan yang dapat dilakukan antara lain adalah menjaga kebersihan mulut, pendidikan kesehatan gigi, diet dan konsumsi gula, penggunaan fluor, dan mengetahui status kesehatan gigi dan mulut, Uraiannya disajikan berikut ini (Panjaitan, 1997; Pintauli \& Hamada, 2007).

\section{Menjaga Kebersihan Mulut}

Penyikatan gigi, penggunaan benang gigi (flossing), dan tindakan profilaksis profesional disadari sebagai komponen dasar dalam menjaga kebersihan mulut. Keterampilan dan metode penyikatan gigi harus lebih ditekankan agar setiap orang mampu membersihkan seluruh giginya. Setiap individu sebaiknya menyikat gigi dua kali sehari segera sesudah sarapan pagi dan sebelum tidur malam dengan pasta gigi yang mengandung fluor. Pemakaian benang gigi juga diperlukan untuk membersihkan daerah celah (interdental) gigi. Tindakan profilaksis profesional seperti skeling dan root planning dilakukan oleh dokter gigi.

\section{Pendidikan Kesehatan Gigi}

Pendidikan Kesehatan adalah upaya untuk mempengaruhi atau mengajak orang lain agar melaksanakan perilaku hidup sehat. Dalam hubungannya dengan perilaku hidup sehat itu penting karena tingkat kesehatan merupakan salah satu faktor yang menentukan Indeks Pembangunan Manusia (IPM). Pendidikan kesehatan gigi tentang kebersihan mulut, diet, konsumsi gula, dan kunjungan berkala ke dokter gigi lebih ditekankan pada anak yang berisiko tinggi terhadap penyakit gigi seperti karies dan penyakit periodontal. Informasi ini sebaiknya bersifat individual dan dilakukan secara terus menerus serta harus menimbulkan motivasi dan tanggung jawab anak untuk memelihara kesehatan mulutnya.

\section{Diet dan Konsumsi Gula}

Tindakan pencegahan karies gigi lebih menekankan ke anak pengurangan konsumsi dan pengendalian frekuensi asupan gula yang tinggi. 
Hal ini dapat dilaksanakan dengan cara memberikan nasehat tentang diet yang baik dan diet bahan pengganti gula. Diet yang dianjurkan adalah memakan makanan yang cukup jumlah protein dan fosfat yang dapat menambah sifat basa dari saliva, memperbanyak makan sayuran dan buah-buahan yang berserat dan berair yang bersifat membersihkan dan merangsang sekresi saliva, menghindari makanan yang manis dan lengket, membatasi frekuensi makan menjadi tiga kali sehari serta menekan keinginan untuk makan di antara jam makan.

\section{Penggunaan Fluor}

Penggunaan fluor dapat dilakukan melalui fluoridasi air minum, pasta gigi dan obat kumur yang mengandung fluor, tablet fluor serta topikal aplikasi fluor. Fluoridasi air minum merupakan cara yang paling efektif untuk menurunkan masalah karies di masyarakat secara umum. Penggunaan obat kumur disarankan untuk anak yang berisiko tinggi atau selama terjadi kenaikan karies. Topikal aplikasi fluor dianjurkan bila penggunaan pasta gigi mengandung fluor, tablet fluor, dan obat kumur tidak cukup untuk mencegah atau menghambat perkembangan karies. Topikal aplikasi fluor diberikan setiap empat atau enam bulan sekali pada anak yang mempunyai risiko karies tinggi.

\section{Metode Penelitian}

Penelitian ini dilakukan pada tahun 2009 di kota Medan secara studi epidemiologi analitik dengan menggunakan desain cross-sectional atau potong lintang. Populasi penelitian adalah seluruh siswa SD dan SMP di Kota Medan. Sampel sekolah di ambil secara stratifikasi-klaster dua tingkat. Tingkat pertama adalah strata klasifikasi wilayah. Kota Medan terdiri atas 21 kecamatan yang digolongkan menjadi 10 kecamatan lingkar dalam dan 11 kecamatan lingkar luar. Selanjutnya, dipilih 4 kecamatan dengan pertimbangan kecamatan tersebut mempunyai daerah yang strategis dan dianggap dapat mewakili seluruh Kecamatan yang ada di Kota Medan. Empat kecamatan terpilih yaitu Kecamatan Medan Baru dan Medan Petisah merupakan kecamatan yang ada di pusat Kota (lingkar dalam) sedangkan Kecamatan Medan Tembung dan Medan Denai merupakan kecamatan yang ada di daerah pinggiran kota (lingkar luar).
Tingkatan kedua adalah klasifikasi SD dan SMP yang berada di wilayah lingkar dalam dan lingkar luar. Pemilihan sekolah (SD dan SMP) dilakukan secara random. Empat sekolah yang mewakili SD dan SMP di wilayah lingkar luar Kota Medan adalah SD Negeri Inpres 064976, SD Swasta Al-Hidayah, kelas SMP Negeri 17, dan SMP Al-Hidayah. Empat sekolah yang mewakili wilayah lingkar dalam Kota Medan adalah SD Negeri 060882, SD Swasta Let.Jend. S. Parman, SMP Negeri 37 Medan, dan SMP Swasta St. Thomas 1 Medan. Menurut WHO, usia 12 dan 15 adalah usia kritis maka penelitian ini hanya ditujukan pada siswa/i kelas VI SD dan kelas III SMP yang dianggap dapat mewakili usia tersebut.

Pengambilan sampel murid dilakukan dengan rumus perhitungan besar sampel sebagai berikut:

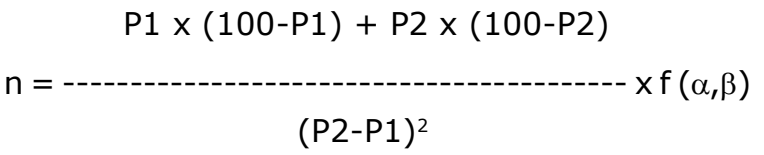

Dari perhitungan besar sampel diperoleh sampel minimum 163,8 orang. Penelitian ini menggunakan sampel sebanyak 393 orang terdiri atas 197 siswa SD dan 196 siswa SMP. Mengingat ada 4 SD terpilih (2 SD Negeri dan 2 SD Swasta) dan 4 SMP (2 SMP Negeri dan 2 SMP Swasta), maka sampel di tiap sekolah masing-masing diambil secara acak sebanyak 50 orang.

Pengumpulan data dilakukan di sekolah dengan wawancara menggunakan pedoman wawancara terstruktur berisi pertanyaan mengenai sosiodemografi dan perilaku siswa dalam memelihara kesehatan gigi dan mulut. Perilaku siswa dikatakan baik apabila $80 \%$ jawaban kuesioner benar, perilaku sedang apabila jawaban yang benar antara $60-80 \%$, dan buruk apabila jawaban yang benar $<60 \%$, dengan menggunakan skala ordinal.

Untuk mendapatkan data DMFT, dilakukan pemeriksaan dengan menggunakan kaca mulut datar dan sonde tajam berbentuk bulan sabit (half moon). Indeks pengukuran yang digunakan adalah indeks DMFT dari WHO.

Penyakit periodontal diukur dengan ada tidaknya perdarahan atau saku periodontal dengan indeks CPI Modified. Pemeriksaan 
dilakukan dengan menggunakan kaca mulut dan prob WHO pada 6 gigi tertentu.

Tingkat kebersihan gigi dan mulut seseorang diukur dengan menggunakan Indeks Oral Higiene menurut Green dan Vermillion, yaitu indeks Oral Higiene Simplified (OHI-S) yang terdiri atas indeks debris dan indeks kalkulus. Untuk mengukur indeks tersebut, gigi yang diperiksa adalah gigi yang telah erupsi sempurna pada 6 gigi tertentu.

\section{Analisis Data}

Analisis data dilakukan dengan menggunakan program SPSS v.15 untuk melihat distribusi variabel yang diteliti dengan menggunakan: 1) Analisis univariat untuk melihat distribusi frekuensi dari tiap variabel guna mendapatkan gambaran umum masing-masing variabel; 2) Analisis bivariat untuk menguji ada tidaknya hubungan faktor perilaku dengan status kesehatan gigi dan mulut siswa digunakan uji one-way ANOVA.

\section{Hasil Penelitian dan Pembahasan}

Secara keseluruhan, dijumpai lebih banyak responden perempuan $(51,40 \%)$, walaupun demikian untuk siswa SD lebih banyak responden laki-laki $(51,27 \%)$ sedangkan untuk siswa SMP lebih banyak responden perempuan yaitu 54,08\% (Tabel 1).

\section{Prevalensi Karies Gigi}

Hasil penelitian menunjukkan bahwa hampir semua anak menderita karies. Hal ini terlihat dari prevalensi secara keseluruhan baik di SD dan SMP Negeri maupun Swasta yang menunjukkan lebih dari $90 \%$ anak menderita karies (Tabel 2), yaitu 92,39\% untuk siswa SD dan 93,37\% untuk siswa SMP.

\section{Pengalaman Karies (DMFT)}

Analisis data memperlihatkan bahwa DMFT pada siswa SD lebih rendah daripada SMP, masingmasing 3,54 $\pm 2,45$ dan 4,20 $\pm 2,92$. Rerata skor gigi decay (gigi yang berlubang) untuk siswa SD lebih rendah $(3,42 \pm 2,36)$ dari rerata SMP yaitu $3,79 \pm 2,69$. sedangkan rerata skor missing (gigi yang hilang) dan filling (gigi yang ditumpat) baik untuk siswa SD dan SMP sangat kecil (Tabel 3).

\section{Status Penyakit Periodontal (CPI-Modified, WHO)}

Dari 6 sekstan yang diperiksa, sebagian besar siswa memilki $>3$ sekstan sehat dengan rerata 3,32 $\pm 2,10$ untuk sekstan yang tidak ada perdarahan bagi siswa SD dan 3,18 $\pm 1,90$ bagi siswa SMP, sedangkan jumlah sekstan yang ada perdarahan berkisar 1-2 sekstan $(2,62 \pm 2,11$ dan $2,64 \pm 1,87$ ) (Tabel 4).

Tabel 1. Karakteristik Responden Siswa SD dan SMP Berdasarkan Jenis Kelamin

\begin{tabular}{|l|c|c|c|}
\hline \multirow{2}{*}{$\begin{array}{l}\text { Satuan } \\
\text { Pendidikan }\end{array}$} & \multicolumn{2}{|c|}{ Jenis Kelamin } & \multirow{2}{*}{ Jumlah Siswa } \\
\cline { 2 - 3 } & Laki-laki & Perempuan & \\
\cline { 2 - 3 } & Jumlah (\%) & Jumlah (\%) & \multirow{2}{*}{197} \\
\hline SD & 101 & 96 & 196 \\
& $(51,27)$ & $148,73)$ & \\
\hline SMP & 90 & $(54,08)$ & 393 \\
& $(45,92))$ & 202 & \\
\hline
\end{tabular}

Tabel 2. Prevalensi Karies Gigi Siswa SD dan SMP

\begin{tabular}{|l|c|c|c|}
\hline \multirow{2}{*}{$\begin{array}{l}\text { Satuan } \\
\text { Pendidikan }\end{array}$} & Ada Karies & Tidak ada Karies & \multirow{2}{*}{ Jumlah Siswa } \\
\cline { 2 - 3 } & Jumlah (\%) & Jumlah (\%) & \\
\hline SD & 182 & 15 & 197 \\
\hline SMP & $(92,39)$ & $(7,61 \%)$ & 196 \\
& 183 & 13 & \\
\hline Total & $(93,37 \%)$ & $(6,63 \%)$ & 393 \\
& 365 & $(7,12)$ & \\
\hline
\end{tabular}


Tabel 3. Rerata Pengalaman Karies (DMFT) pada Siswa SD dan SMP

\begin{tabular}{|l|c|c|c|c|c|}
\hline \multirow{2}{*}{$\begin{array}{l}\text { Satuan } \\
\text { Pendidikan }\end{array}$} & $\begin{array}{c}\text { Decay } \\
(\mathrm{X} \pm \text { SD })\end{array}$ & $\begin{array}{c}\text { Missing } \\
(\mathrm{X} \pm \mathrm{SD})\end{array}$ & $\begin{array}{c}\text { Filling } \\
(\mathrm{X} \pm \mathrm{SD})\end{array}$ & $\begin{array}{c}\text { DMFT } \\
(\mathrm{X} \pm \mathrm{SD})\end{array}$ & Siswa \\
\hline SD & $3,42 \pm 2,36$ & $0,11 \pm 0,39$ & $0,06 \pm 0,41$ & $3,54 \pm 2,45$ & 197 \\
\hline SMP & $3,79 \pm 2,69$ & $0,28 \pm 0,69$ & $0,17 \pm 1,01$ & $4,20 \pm 2,92$ & 196 \\
\hline
\end{tabular}

Tabel 4. Rerata Sekstan Yang Terkena Penyakit Periodontal Pada Siswa SD dan SMP Berdasarkan Ada Tidaknya Perdarahan

\begin{tabular}{|l|c|c|c|c|}
\hline \multirow{3}{*}{$\begin{array}{l}\text { Satuan } \\
\text { Pendidikan }\end{array}$} & \multicolumn{4}{|c|}{ Rata-rata Perdarahan (sekstan) } \\
\cline { 2 - 5 } & \multicolumn{2}{|c|}{ Tidak ada perdarahan } & $\mathrm{X}$ & SD \\
\cline { 2 - 5 } & $\mathrm{X}$ & $\mathrm{SD}$ & 2,62 & 2,11 \\
\hline SD & 3,32 & 2,10 & 2,64 & 1,87 \\
\hline SMP & 3,18 & 1,90 & \\
\hline
\end{tabular}

Oleh karena saku periodontal tidak dijumpai pada anak SD, maka pengukuran rerata mean dan SD tidak dihitung. Jumlah sekstan yang tidak ada saku (sekstan sehat) antara 3-4 sekstan. Jumlah sekstan yang mempunyai kedalaman saku 4-5 $\mathrm{mm}$ hanya 0-1 sekstan, begitu juga dengan kedalaman saku $>6 \mathrm{~mm}$, yaitu tidak lebih dari 1 sekstan (Tabel 5 ).

\section{Status Kebersihan Rongga Mulut (OHIS)}

Sebagian besar siswa SD dan SMP memiliki skor oral higiene yang sedang, dengan rerata untuk siswa SMP 2,68 $\pm 0,31$ yaitu $52,6 \%$ dan untuk

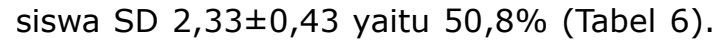

\section{Perilaku Kebersihan Gigi dan Mulut}

Dari pemeriksaan perilaku kebersihan gigi dan mulut, baik siswa SD maupun SMP semuanya sudah mempunyai sikat gigi, walaupun demikian belum semuanya mempunyai sikat gigi sendiri, terlihat bahwa 11,7\% siswa SD dan 9,2\% siswa SMP masih mempunyai sikat gigi bersama. Sebahagian siswa SD sudah memiliki kebiasaan menyikat gigi sesudah sarapan yaitu sekitar $51,8 \%$

Tabel 5. Rerata Sekstan Yang Terkena Penyakit Periodontal Pada Siswa SD dan SMP Berdasarkan Kedalaman Saku

\begin{tabular}{|l|c|c|c|c|c|c|}
\hline \multirow{3}{*}{$\begin{array}{l}\text { Satuan } \\
\text { Pendidikan }\end{array}$} & \multicolumn{6}{|c|}{ Rerata Kedalaman Saku (sekstan) } \\
\cline { 2 - 7 } & \multicolumn{2}{|c|}{$\begin{array}{l}\text { Tidak ada saku } \\
\text { (Sekstan sehat) }\end{array}$} & \multicolumn{2}{|c|}{ Saku 4-5mm } & \multicolumn{2}{c|}{ Saku $>6 \mathrm{~mm}$} \\
\cline { 2 - 7 } & $\mathrm{X}$ & SD & $\mathrm{X}$ & SD & $\mathrm{X}$ & SD \\
\hline SD & - & - & - & - & - & - \\
\hline SMP & 2,61 & 0,85 & 0,23 & 0,59 & 0,02 & 0,12 \\
\hline
\end{tabular}

Tabel 6. Rerata dan Kategori Skor Oral Higiene (OHIS) Pada Siswa SD dan SMP

\begin{tabular}{|l|c|c|c|c|c|c|}
\hline \multirow{3}{*}{$\begin{array}{l}\text { Satuan } \\
\text { Pendidikan }\end{array}$} & \multicolumn{6}{|c|}{ Oral Higiene Indeks } \\
\cline { 2 - 7 } & \multicolumn{2}{|c|}{ Baik } & \multicolumn{2}{c|}{ Sedang } & \multicolumn{2}{c|}{ Buruk } \\
\cline { 2 - 7 } & $\mathrm{X} \pm \mathrm{SD}$ & $\begin{array}{c}\text { Jlh } \\
(\%)\end{array}$ & $\mathrm{X} \pm \mathrm{SD}$ & $\begin{array}{c}\text { Jlh } \\
(\%)\end{array}$ & $\mathrm{X} \pm \mathrm{SD}$ & $\begin{array}{c}\text { Jlh } \\
(\%)\end{array}$ \\
\hline SD & $1,16 \pm 0,01$ & $\begin{array}{c}12 \\
(6,1)\end{array}$ & $2,33 \pm 0,43$ & $\begin{array}{c}100 \\
(50,8)\end{array}$ & $3,66 \pm 0,57$ & $\begin{array}{c}85 \\
(43,1)\end{array}$ \\
\hline SMP & $0,66 \pm 0,01$ & $\begin{array}{c}18 \\
(9,1)\end{array}$ & $2,68 \pm 0,31$ & $\begin{array}{c}103 \\
(52,6)\end{array}$ & $3,87 \pm 0,72$ & 75 \\
& & & & & \\
& & & & & &
\end{tabular}


dan kebiasaan menyikat gigi pada malam hari sebelum tidur yaitu $67,5 \%$ sedangkan pada siswa SMP hanya $36,9 \%$ sesudah sarapan dan $44,9 \%$ sebelum tidur malam. Bila dilihat dari cara menyikat gigi, siswa SD dan SMP umumnya memiliki kesamaan (>90\%) dalam hal cara menyikat gigi yaitu gerakan maju mundur, pendek-pendek, seluruh permukaan gigi. Dalam hal rutinitas mengganti sikat gigi, siswa SD lebih banyak mengganti sikat gigi jika bulu sikat gigi sudah rusak/mengembang $(91,4 \%)$, sedangkan siswa SMP $74,5 \%$. Hanya sebagian kecil $(8,6 \%)$ siswa SD masih mengganti sikat giginya dengan waktu tidak tentu (Tabel 7).
Berdasarkan rutinitas kunjungan ke dokter gigi terlihat lebih banyak siswa SD memeriksakan giginya ke dokter gigi secara teratur, yaitu setiap 6 bulan sekali dengan presentase 56,9\% sedangkan pada siswa SMP hanya $18,4 \%$. Sebanyak 20,9\% siswa SMP tidak pernah memeriksakan giginya secara teratur, sedangkan di SD hanya $8,1 \%$ (Tabel 8 ).

Dalam membersihkan dan memelihara kesehatan gigi, bila gigi kotor atau gusi berdarah, maka siswa SD $(63,5 \%)$ memeriksakan dan membersihkan karang gigi ke puskesmas/dokter gigi sedangkan siswa SMP hanya 38,8\%. Hanya

Tabel 7. Perilaku Siswa SD dan SMP Terhadap Kepemilikan dan Kebiasaan Menyikat Gigi

\begin{tabular}{|c|c|c|c|c|}
\hline \multirow{2}{*}{$\begin{array}{l}\text { Kepemilikan dan Kebiasaan Menyikat } \\
\text { Gigi }\end{array}$} & \multicolumn{2}{|c|}{ SD } & \multicolumn{2}{|c|}{ SMP } \\
\hline & Jumlah & $\%$ & Jumlah & $\%$ \\
\hline $\begin{array}{l}\text { Kepemilikan sikat gigi } \\
\text { - Ya, punya sendiri } \\
\text { - Ya, punya bersama } \\
\text { - Tidak punya }\end{array}$ & $\begin{array}{c}174 \\
23 \\
0\end{array}$ & $\begin{array}{c}88,3 \\
11,7 \\
0\end{array}$ & $\begin{array}{c}178 \\
18 \\
0\end{array}$ & $\begin{array}{c}90,8 \\
9,2 \\
0\end{array}$ \\
\hline $\begin{array}{l}\text { Setiap pagi menyikat gigi } \\
\text { - Ya, sesudah sarapan } \\
\text { - Ya, sebelum sarapan } \\
\text { - Sekali-sekali }\end{array}$ & $\begin{array}{c}102 \\
84 \\
11\end{array}$ & $\begin{array}{c}51,8 \\
42,6 \\
5,6\end{array}$ & $\begin{array}{c}72 \\
109 \\
15\end{array}$ & $\begin{array}{c}36,9 \\
55,9 \\
7,2\end{array}$ \\
\hline $\begin{array}{l}\text { Malam sebelum tidur menyikat gigi } \\
\text { - Ya, setiap hari. } \\
\text { - Ya, sekali-sekali apabila tidak lupa } \\
\text { - Tidak pernah. }\end{array}$ & $\begin{array}{c}133 \\
55 \\
9\end{array}$ & $\begin{array}{c}67,5 \\
27,9 \\
4,6\end{array}$ & $\begin{array}{c}88 \\
101 \\
7\end{array}$ & $\begin{array}{c}41,9 \\
51,5 \\
3,6\end{array}$ \\
\hline $\begin{array}{l}\text { Gerakan menyikat gigi } \\
\text { - Maju mundur, pendek-pendek, } \\
\text { seluruh permukaan gigi } \\
\text { - Menyikat gigi dengan kuat, } \\
\text { panjang-panjang, dan seluruh } \\
\text { permukaan. } \\
\text { - Maju mundur, pendek-pendek, } \\
\text { tidak seluruh permukaan. }\end{array}$ & $\begin{array}{c}181 \\
11\end{array}$ & $\begin{array}{l}91,9 \\
5,6\end{array}$ & $\begin{array}{c}190 \\
5\end{array}$ & $\begin{array}{c}96,9 \\
3\end{array}$ \\
\hline $\begin{array}{l}\text { Mengganti sikat gigi. } \\
\text { - Jika bulu sikat sudah rusak/sudah } \\
\text { mengembang. } \\
\text { - Tidak tentu }\end{array}$ & $\begin{array}{c}180 \\
17\end{array}$ & $\begin{array}{r}91,4 \\
8,6\end{array}$ & $\begin{array}{c}146 \\
50\end{array}$ & $\begin{array}{l}74,5 \\
25,5\end{array}$ \\
\hline
\end{tabular}

Tabel 8. Perilaku Siswa SD dan SMP Berdasarkan Rutinitas Kunjungan ke Dokter Gigi

\begin{tabular}{|l|c|c|c|c|}
\hline \multirow{2}{*}{ Pemeriksaan Gigi Secara Teratur } & \multicolumn{2}{|c|}{ SD } & \multicolumn{2}{c|}{ SMP } \\
\cline { 2 - 5 } & Jumlah & $\%$ & Jumlah & $\%$ \\
\hline - Ya, setiap 6 bulan sekali. & 112 & 56,9 & 36 & 18,4 \\
- Ya, tidak tentu. & 69 & 35 & 119 & 60,7 \\
& 16 & 8,1 & 41 & 20,9 \\
\hline
\end{tabular}


sedikit responden yang membiarkan, tidak melakukan apa-apa terhadap gigi atau gusi mereka yang berdarah, yaitu siswa SD 1,5\% sedangkan siswa SMP 3,6\% (Tabel 9).

Untuk tindakan dalam memelihara kesehatan gigi dan mulut baik siswa SD maupun SMP mempunyai persentase yang tinggi pada tindakan menyikat gigi secara teratur dan membersihkan lidah yaitu $57,9 \%$ untuk siswa SD dan $45,4 \%$ untuk siswa SMP (Tabel 10).

Hasil penelitian menunjukkan bahwa siswa SD umumnya mempunyai perilaku pemeliharaan kesehatan gigi dan mulut yang baik, terlihat bahwa persentase perilaku 'baik' pada siswa SD $(61,4 \%)$, sedangkan pada siswa SMP lebih banyak persentase perilaku 'sedang' (59,2\%) Hanya 8,6\% siswa SD dan $10,7 \%$ siswa SMP yang dikatakan mempunyai perilaku pemeliharaan kesehatan gigi dan mulut yang dikategorikan 'buruk' (Tabel 11).

\section{Hubungan Perilaku Pemeliharaan Terhadap Status Kesehatan Gigi dan Mulut}

Hasil penelitian menunjukkan bahwa siswa SD dan SMP yang mempunyai perilaku yang baik mempunyai skor DMFT yang baik pula. Hasil analisis menunjukkan ada hubungan yang signifikan antara perilaku pemeliharaan dengan skor DMFT $(p<0,05)$ (Tabel 12). Dalam hubungannya dengan status peridontal terlihat bahwa tidak ada hubungan antara perilaku

Tabel 9. Perilaku Siswa SD dan SMP Terhadap Gigi Kotor atau Gusi Sering Berdarah

\begin{tabular}{|l|c|c|c|c|}
\hline Tindakan yang Dilakukan Bila Gigi Kotor & \multicolumn{2}{|c|}{ SD } & \multicolumn{2}{c|}{ SMP } \\
\cline { 2 - 5 } atau Gusi Sering Berdarah. & Jumlah & $\%$ & Jumlah & $\%$ \\
\hline - Memeriksakan dan membersihkan & & & & \\
karang gigi ke puskesmas/drg. & 125 & 63,5 & 76 & 38,8 \\
- Menggosok gigi. & 44 & 22,3 & 68 & 34,7 \\
- Berkumur menggunakan obat kumur & 25 & 12,7 & 45 & 23 \\
- Dibiarkan & 3 & 1,5 & 7 & 3,6 \\
& & & & \\
\hline
\end{tabular}

Tabel 10. Perilaku Siswa SD dan SMP Berdasarkan Tindakan Pemeliharaan Kesehatan Gigi dan Mulut

\begin{tabular}{|l|c|c|c|c|}
\hline Tindakan yang Dilakukan dalam Memelihara & \multicolumn{2}{|c|}{ SD } & \multicolumn{2}{c|}{ SMP } \\
\cline { 2 - 5 } Kesehatan Gigi dan Mulut & Jumlah & $\%$ & Jumlah & $\%$ \\
\hline - Menyikat gigi secara teratur dan & & & & \\
membersihkan lidah. & 114 & 57,9 & 89 & 45,4 \\
- Hanya menyikat gigi secara teratur. & & & & \\
- Hanya berkumur dengan obat kumur. & 36 & 18,3 & 45 & 23 \\
- Menyikat gigi saja secara teratur dan & 1 & 0,5 & 3 & 1,5 \\
berkumur dengan obat kumur. & 46 & 23,4 & 59 & 30,1 \\
\hline
\end{tabular}

Tabel 11. Kategori Perilaku Pemeliharaan Kesehatan Gigi dan Mulut Pada Siswa SD dan SMP

\begin{tabular}{|l|c|c|c|c|c|c|c|}
\hline \multirow{3}{*}{$\begin{array}{l}\text { Satuan } \\
\text { Sekolah }\end{array}$} & \multicolumn{4}{|c|}{ Perilaku } & \multirow{2}{*}{$\begin{array}{c}\text { Jumlah } \\
\text { Siswa }\end{array}$} \\
\cline { 2 - 7 } & \multicolumn{2}{|c|}{ Baik } & \multicolumn{2}{c|}{ Sedang } & \multicolumn{2}{c|}{ Buruk } & \\
\cline { 2 - 7 } & Jumlah & $\%$ & Jumlah & $\%$ & Jumlah & $\%$ & \\
\hline SD & 121 & 61,4 & 59 & 29,9 & 17 & 8,6 & 197 \\
\hline SMP & 59 & 30,1 & 116 & 59,2 & 21 & 10,7 & 196 \\
\hline
\end{tabular}


pemeliharaan dengan status periodontal, baik perdarahan maupun kedalaman saku $(p>0,05)$ (Tabel 13 dan Tabel 14), sedangkan untuk skor kebersihan mulut dijumpai adanya hubungan perilaku pemeliharaan dengan skor OHIS $(p<0,05)$ (Tabel 15).

\section{Hasil Penelitian dan Pembahasan}

Pada penelitian ini terlihat bahwa prevalensi karies siswa SD dan SMP sangat tinggi (>90\%). Hal ini menunjukkan bahwa penyakit karies pada anakanak masih merupakan masalah penyakit gigi dan mulut yang perlu tetap menjadi perhatian

Tabel 12. Hubungan Perilaku Pemeliharaan Terhadap DMFT Pada Siswa SD dan SMP

\begin{tabular}{|c|c|c|c|c|}
\hline \multirow{2}{*}{$\begin{array}{l}\text { Perilaku } \\
\text { Pemeliharaan }\end{array}$} & \multirow[b]{2}{*}{$\mathrm{N}$} & \multicolumn{3}{|c|}{ DMFT } \\
\hline & & $\bar{x}$ & SD & Hasil analisis statistik \\
\hline $\begin{aligned} & \text { Siswa SD } \\
& \text { - } \text { Baik } \\
& \text { - } \text { Sedang } \\
& \text { - } \text { Buruk }\end{aligned}$ & $\begin{array}{c}121 \\
59 \\
17\end{array}$ & $\begin{array}{l}3,34 \\
3,69 \\
4,47\end{array}$ & $\begin{array}{l}2,70 \\
2,79 \\
2,76\end{array}$ & $\begin{array}{c}F=3,36 \\
d f=194 \\
p=0,03 *\end{array}$ \\
\hline Total & 197 & 3,54 & 2,45 & \\
\hline $\begin{aligned} \text { Siswa } & \text { SMP } \\
\bullet & \text { Baik } \\
\bullet & \text { Sedang } \\
\bullet & \text { Buruk } \\
\text { Total } & \end{aligned}$ & $\begin{array}{c}59 \\
116 \\
21 \\
196\end{array}$ & $\begin{array}{l}3,54 \\
4,23 \\
5,86 \\
4,20\end{array}$ & $\begin{array}{l}1,99 \\
2,66 \\
5,18 \\
29\end{array}$ & $\begin{array}{c}F=5,07 \\
d f=193 \\
p=0,007 *\end{array}$ \\
\hline
\end{tabular}

*signifikan

Tabel 13. Hubungan Perilaku Pemeliharaan Terhadap Ada Tidaknya Perdarahan Pada Siswa SD dan SMP

\begin{tabular}{|c|c|c|c|c|c|c|c|}
\hline \multirow{3}{*}{$\begin{array}{l}\text { Perilaku } \\
\text { Pemeliharaan }\end{array}$} & \multicolumn{7}{|c|}{ Status Periodontal (Ada Tidaknya Perdarahan) } \\
\hline & \multirow[b]{2}{*}{$\mathrm{N}$} & \multicolumn{3}{|c|}{ Sekstan 0} & \multicolumn{3}{|c|}{ Sekstan 1} \\
\hline & & $\mathrm{X}$ & SD & $\begin{array}{c}\text { Hasil } \\
\text { Analisis } \\
\text { statistik }\end{array}$ & $X$ & SD & $\begin{array}{c}\text { Hasil } \\
\text { Analisis } \\
\text { statistik }\end{array}$ \\
\hline Siswa SD & & & & \multirow{5}{*}{$\begin{array}{l}F=1,06 \\
d f=239 \\
p=0,35\end{array}$} & & & \multirow{5}{*}{$\begin{array}{l}F=0,78 \\
d f=239 \\
p=0,45\end{array}$} \\
\hline Baik & 121 & & 1,98 & & ,21 & 0,65 & \\
\hline Sedang & 59 & 5,17 & 1,83 & & 0,17 & 0,87 & \\
\hline Buruk & 17 & 5,12 & 1,76 & & 0,3 & 0,17 & \\
\hline Total & 197 & 4,97 & 1,90 & & 0,17 & 0,70 & \\
\hline Siswa SMP & & & & \multirow{5}{*}{$\begin{array}{c}F=1,85 \\
d f=193 \\
p=0,15\end{array}$} & & & \multirow{5}{*}{$\begin{array}{l}F=2,43 \\
d f=193 \\
p=0,91\end{array}$} \\
\hline Baik & 59 & 3,54 & 1,83 & & 2,22 & 1,80 & \\
\hline Sedang & 116 & 3,09 & 1,84 & & 2,78 & 1,84 & \\
\hline Buruk & 21 & 2,71 & 2,30 & & 3,10 & 2,23 & \\
\hline Total & 196 & 4,81 & 1,93 & & 2,64 & 1,87 & \\
\hline
\end{tabular}

Tabel 14. Hubungan Perilaku Pemeliharaan Terhadap Kedalaman Saku Pada Siswa SMP

\begin{tabular}{|c|c|c|c|c|c|c|c|c|c|c|}
\hline \multirow{3}{*}{$\begin{array}{l}\text { Perilaku } \\
\text { Pemeliharaan }\end{array}$} & \multicolumn{10}{|c|}{ Status Periodontal (Kedalaman Saku) } \\
\hline & \multirow[b]{2}{*}{$\mathrm{N}$} & \multicolumn{3}{|c|}{ Sekstan 0} & \multicolumn{3}{|c|}{ Sekstan 1} & \multicolumn{3}{|c|}{ Sekstan 2} \\
\hline & & $\mathrm{X}$ & SD & $\begin{array}{c}\text { Hasil } \\
\text { Analisis } \\
\text { statistik }\end{array}$ & $\mathrm{X}$ & SD & $\begin{array}{c}\text { Hasil } \\
\text { Analisis } \\
\text { statistik }\end{array}$ & $\mathrm{X}$ & SD & $\begin{array}{c}\text { Hasil } \\
\text { Analisis } \\
\text { statistik }\end{array}$ \\
\hline Siswa SMP & & & & \multirow{5}{*}{$\begin{array}{l}\mathrm{F}=0,33 \\
\mathrm{df}=193 \\
\mathrm{p}=0,71\end{array}$} & & & \multirow{5}{*}{$\begin{array}{l}F=2,59 \\
d f=193 \\
p=0,07\end{array}$} & & & \multirow{5}{*}{$\begin{array}{c}F=1,00 \\
d f=193 \\
p=0,36\end{array}$} \\
\hline Baik & 59 & 5,68 & 0,65 & & 0,14 & 0,34 & & 0,03 & 0,18 & \\
\hline Sedang & 116 & 5,59 & 0,92 & & 0,23 & 0,60 & & 0,01 & 0,09 & \\
\hline Buruk & 21 & 5,52 & 0,92 & & 0,48 & 0,92 & & 0,00 & 0,00 & \\
\hline Total & 196 & 5,61 & 0,85 & & 0,23 & 0,59 & & 0,02 & 0,12 & \\
\hline
\end{tabular}


Tabel 15. Hubungan Perilaku Pemeliharaan Terhadap Skor Kebersihan Mulut (OHIS) Pada Siswa SD dan SMP

\begin{tabular}{|c|c|c|c|c|}
\hline \multirow{2}{*}{$\begin{array}{l}\text { Perilaku } \\
\text { Pemeliharaan }\end{array}$} & \multirow[b]{2}{*}{$\mathrm{N}$} & \multicolumn{3}{|c|}{ Status Kebersihan Mulut (OHIS) } \\
\hline & & $\mathrm{X}$ & SD & Hasil analisis statistik \\
\hline $\begin{array}{cl}\text { Siswa SD } \\
\bullet & \text { Baik } \\
\bullet & \text { Sedang } \\
\bullet & \text { Buruk } \\
\end{array}$ & $\begin{array}{c}121 \\
59 \\
17 \\
\end{array}$ & $\begin{array}{l}2,76 \\
3,64 \\
3,91 \\
\end{array}$ & $\begin{array}{l}1,01 \\
0,77 \\
0,48 \\
\end{array}$ & $\begin{array}{c}F=13,47 \\
d f=194 \\
p=0,00^{*}\end{array}$ \\
\hline Total & 197 & 2,82 & 0,97 & \\
\hline $\begin{array}{cl}\text { Siswa SMP } \\
\text { - } & \text { Baik } \\
\text { - } & \text { Sedang } \\
\text { - } & \text { Buruk } \\
\end{array}$ & $\begin{array}{c}59 \\
116 \\
21\end{array}$ & $\begin{array}{l}2,86 \\
2,82 \\
3,64\end{array}$ & $\begin{array}{l}1,02 \\
1,01 \\
1,20\end{array}$ & $\begin{array}{c}F=4,86 \\
d f=193 \\
p=0,04^{*}\end{array}$ \\
\hline Total & 196 & 2,82 & 1,02 & \\
\hline
\end{tabular}

sehingga dapat diupayakan tindakan pencegahannya. Tindakan pencegahan tidak hanya mencegah seseorang dari penyakit tertentu saja tetapi juga dapat meminimalkan biaya perawatan yang mahal dan menghindari komplikasi penyakit gigi yang membahayakan. Prevalensi pada siswa SMP lebih tinggi daripada siswa SD (Tabel 2), hal ini berarti dengan bertambahnya umur, maka makin banyak yang menderita karies. Dari hasil Survei Kesehatan Rumah Tangga (2001) diperoleh prevalensi pengalaman karies (DMFT) yang cenderung meningkat dengan bertambahnya umur yaitu $43,9 \%$ umur 12 tahun sampai mencapai $80,1 \%$ pada usia 35-44 tahun (DepKes RI, 2001).

Bila dilihat dari pengalaman karies (DMFT), baik siswa SD maupun SMP mempunyai rerata yang masih jauh dari target pencapaian gigi sehat WHO tahun 2010 di mana DMFT pada usia 12 tahun mempunyai $D M F T=1$. Kenyataan lain bahwa rerata gigi yang ditambal (F) pada siswa SD dan SMP sangat kecil yaitu masing-masing $0,08 \pm 0,52$ dan $0,06 \pm 0,50$. Hal ini menunjukkan bahwa usaha kuratif masih sangat rendah dibandingkan tingginya jumlah gigi yang mengalami karies (D) baik pada siswa SD dan SMP. Salah satu alasan yang mungkin menyebabkan hal ini adalah tingginya biaya perawatan gigi. Dalam The World Oral Health Report (WHO, 2003) dinyatakan bahwa penyakit gigi dan mulut menempati peringkat keempat penyakit termahal dalam pengobatan.

Secara umum status periodontal pada siswa SD dan SMP terpilih menunjukkan bahwa siswa mempunyai lebih banyak sekstan gigi yang sehat
$(4,14 \pm 1,98$ pada siswa SD dan siswa SMP $3,77 \pm 1,73)$ daripada sekstan yang mempunyai perdarahan ataupun saku periodontal (Tabel 4,5) yang artinya bahwa setiap murid mempunyai sekstan gusi sehat $>3$. Rerata sekstan yang mempunyai kedalaman saku $>6 \mathrm{~mm}$ sangat kecil $(0,01 \pm 0,10)$, sudah sesuai dengan target pencapaian gigi sehat tahun 2010 WHO yaitu penduduk dengan saku yang dalam $<1$ sekstan. Walaupun demikian, upaya edukasi perlu tetap dilakukan agar siswa mempunyai kebiasaan pelihara diri yang berkesinambungan.

Rerata skor kebersihan mulut baik pada siswa SD maupun SMP lebih banyak berada dalam kategori sedang, sedangkan kategori baik masih sangat sedikit (Tabel 6). Hal ini mungkin disebabkan masih banyak siswa yang pada pagi hari menyikat gigi sebelum sarapan pagi (Tabel 7).

Hasil penelitian menunjukkan bahwa siswa SD memiliki perilaku pemeliharaan kesehatan gigi dan mulut lebih banyak dalam kategori baik daripada siswa SMP. Peneliti berasumsi bahwa perilaku pemeliharaan kesehatan gigi dan mulut siswa SD memiliki perilaku pemeliharaan kesehatan gigi dan mulut lebih baik karena siswa sekolah dasar sudah menjalankan program Usaha Kesehatan Gigi Sekolah (UKGS). Program UKGS merupakan suatu kegiatan yang sangat relevan dalam pelaksanaan upaya penanggulangan penyakit gigi dan mulut karena kegiatannya diarahkan kepada penanaman kebiasaan pemeliharaan kesehatan gigi dan mulut sejak dini, yang diharapkan akan berpengaruh terhadap kondisi kesehatan gigi dan mulutnya di kemudian hari (Depkes RI, 2004). 
Perilaku siswa terhadap waktu menyikat gigi pada siswa SD dan SMP menunjukkan bahwa masih banyak yang belum tepat yaitu pada waktu mandi, sebelum sarapan pagi ( $42,6 \%$ dan $55,9 \%$ ) dengan alasan tidak sempat bila dilakukan setelah sarapan pagi. Hal ini mungkin disebabkan waktu masuk sekolah pagi, sehingga kemungkinan sikat gigi bila setelah sarapan pagi. Sedangkan pada malam hari, sudah banyak siswa SD yang melakukan sikat gigi sebelum tidur $(67,5 \%)$ sebaliknya pada siswa SMP hanya $41,9 \%$. Terlihat bahwa persentase siswa SMP yang sekali-sekali menyikat gigi apabila tidak lupa lebih banyak yaitu $51,5 \%$ (Tabel 8).

Untuk kepemilikan sikat gigi, semua siswa SD dan SMP sudah mempunyai sikat gigi, walaupun demikian masih ada $11,7 \%$ pada siswa SD dan 9,2\% pada siswa SMP yang memiliki sikat gigi bersama. Sebaiknya seorang anak memiliki sikat gigi sendiri sehingga terhindar dari kemungkinan kontaminasi bakteri bila menggunakan sikat gigi bersama.

Persentase siswa SD yang melakukan pemeriksaan gigi secara rutin yaitu setiap 6 bulan sekali lebih banyak daripada siswa SMP. Hal ini mungkin disebabkan keterlibatan orangtua pada anak SD lebih dominan daripada anak SMP yang dianggap sudah lebih mandiri dalam melakukan pemeliharaan kesehatan gigi (Tabel 8). Hal ini terlihat dari tindakan yang dilakukan siswa SMP bila giginya kotor atau sering berdarah di mana persentase siswa SMP yang menggunakan obat kumur lebih banyak daripada siswa SD (Tabel 9\&10).

Hasil analisis menunjukkan terdapat hubungan yang bermakna antara perilaku pemeliharaan kesehatan gigi dan mulut baik pada siswa SD maupun SMP dengan status pengalaman karies (DMFT) dan status kebersihan mulut $(p<0,05)$. Hal ini menunjukkan bahwa siswa sekolah SD dan SMP yang memiliki perilaku baik memiliki status DMFT yang rendah. Dengan kata lain kemungkinan bahwa pemeliharaan kesehatan gigi sudah menjadi gaya hidup siswa. Walaupun demikian, tidak terlihat adanya hubungan antara perilaku pemeliharaan dengan status periodontal $(p>0,05)$. Banyak faktor yang mempengaruhi terjadinya penyakit periodontal seperti oral higiene yang buruk, umur dan jenis kelamin.
Hingga saat ini, Departemen Kesehatan Republik Indonesia telah melakukan transformasi kebijakan di bidang kesehatan dengan "Paradigma Sehat" yaitu suatu kondisi masyarakat Indonesia yang ditandai dengan penduduk yang hidup dalam lingkungan dan perilaku hidup sehat, mampu menjangkau pelayanan kesehatan yang bermutu, adil dan merata serta memiliki derajat kesehatan yang setinggi-tingginya. Tindakan peningkatan kesehatan dapat dimulai dari diri si anak sendiri yaitu dengan pola hidup sehat dan menjaga kebersihan mulutnya. Menurut Hurlock (1978), orangtua dan guru mempunyai peran terhadap perubahan perilaku anak dalam memelihara kesehatannya, termasuk memelihara kesehatan gigi. Orangtua mempunyai peran yang sangat penting dalam perawatan gigi anak-anaknya misalnya memberi contoh perawatan gigi, memotivasi merawat gigi, mengawasi perawatan gigi, dan membawa anak ke dokter gigi jika anak sakit gigi (Suwelo, 1992). Selain itu, perkembangan seorang anak ditentukan oleh sifat hubungan antara anak dengan anggota keluarga terutama ibu. Ibu rumah tangga merupakan tokoh kunci dalam keluarga karena berperan penting dalam perilaku kesehatan keluarga (Pintauli dan Melur, 2004). Peran ini sangat penting oleh karena bila anak belum memiliki kebiasaan yang baik maka pengawasan dari orang tua harus terus dilakukan.

\section{Simpulan dan Saran}

\section{Simpulan}

Dari hasil penelitian dapat disimpulkan bahwa status kesehatan gigi dan mulut siswa SD dan SMP masih perlu diberikan perhatian. Adanya hubungan yang siginifikan antara perilaku pemeliharaan dengan status DMFT dan OHIS menunjukkan bahwa perilaku yang baik mempunyai skor DMFT dan OHIS yang rendah. Walaupun demikian, upaya promosi dan edukasi perlu tetap dilakukan agar perilaku pemeliharaan yang sudah baik tetap dapat dipertahankan.

Dengan diperolehnya gambaran informasi perilaku dan status kesehatan gigi dan mulut siswa SD dan SMP, maka dapat dilakukan evaluasi terhadap program kesehatan gigi yang sudah dilaksanakan. 


\section{Saran}

Mengacu pada simpulan penelitian, disarankan kepada Dinas Kesehatan Kota khususnya Kota Medan, sebagai pengelola program dapat merencanakan dan menyusun Kebijakan Usaha Kesehatan Gigi Sekolah (UKGS) agar dalam upaya pengembangan program peningkatan pemeliharaan kesehatan gigi dan mulut. Selain itu, Dinas Kesehatan perlu bekerja sama melalui lintas sektoral yaitu dengan Dinas Pendidikan misalnya dalam upaya meningkatkan promosi dan edukasi tentang pemeliharaan kebersihan mulut dengan cara menyikat gigi untuk anak sekolah. Kemitraan Dinas Kesehatan dengan Dinas Pendidikan Kota/ Kabupaten juga diperlukan dalam menggiatkan pelaksanaan program UKGS yang terintegrasi dengan Usaha Kesehatan Sekolah.

\section{Pustaka Acuan}

Axelsson P. 1999. An introduction to risk prediction and preventive dentistry. Chicago: Quinressence Publishing Co., Inc., 113-114.

Astoeti, Tri Erri. 2006. Total Quality Management dalam Pendidikan Kesehatan Gigi di sekolah. Jakarta: PT Raja Grafindo Persada: 20-30.

Budiharto. 1998. Kontribusi umur, pendidikan, jumlah anak, status ekonomi keluarga, pemanfaatan fasilitas kesehatan gigi dan pendidikan kesehatan gigi terhadap perilaku ibu, JKGUI; 5(2): 92-108.

Departemen Kesehatan RI. 2000. Pedoman Pelaksanaan Kesehatan Gigi Sekolah. Indonesia Sehat 2010. Jakarta.

Departemen Kesehatan RI. 2001. Profil Kesehatan Gigi dan Mulut di Indonesia pada Pelita VI. Dirjen Pelayanan Medik Direktorat Kesehatan Gigi. Jakarta.

Departemen Kesehatan RI. 2004. Pedoman Penyelenggaraan Usaha Kesehatan Gigi Sekolah. Jakarta.

Departemen Kesehatan RI. 2008. Riset Kesehatan Dasar (Riskesdas). Jakarta: Badan Litbangkes.

Dinas Kesehatan Kota Medan. 2008. Profil Dinas Kesehatan Kota tahun 2007. Medan: 1-15.

Debnath T. 2002. Ashok'S Public Health and Preventive Dentistry. 2nd ed., India: AITBS Publishers \& Distributors (Regd.): 8-30.

Herijulianti, E. Indriani, TS., dan Sri Artini. 2001. Pendidikan Kesehatan Gigi. Jakarta: Penerbit Buku Kedokteran: 97-115.

Hurlock, E.B. 1978. Perkembangan anak. Jilid 2. Alih Bahasa. Tjandrasa, M. Jakarta: Erlangga: 202-7.

Irmawati., dan Satiti, K. 2001. Prevalensi karies pada anak-anak yang tinggal di tiga desa dengan konsumsi air minum yang berbeda kadar fluornya. Majalah Kedokteran Gigi (Dental Journal) FKG UNAIR: $147-50$.

Murphy, E.M. 2004. Promoting Healthy Behaviour. Health Bulletin. Population Refrences Bureau: 1-7.

Octiara, E. dan Roesnawati, Y. 2001. Karies gigi, oral higiene dan kebiasaan membersihkan gigi pada anak-anak Panti Karya Pungai di Binjai. J Kedokteran Gigi UI; 6(1): 18-23.

Panjaitan, M. 1997. Etiologi karies gigi dan penyakit periodontal. Ed ke-1. Medan: USU Press: 30-53.

Peterson, PE. 2003. The World Oral Health Report 2003: Continuous improvement of oral health in the $21^{\text {st }}$ century-the approach of the WHO Global Oral Health Programme. Community Dent Oral Epidemiology; 31 (suppl): 3-8.

Pintauli, S. dan Melur, T. 2004. Hubungan tingkat pendidikan dan skor DMFT pada ibu-ibu rumah tangga berusia 20-45 tahun di Kecamatan Medan Tuntungan. Dentika Dental Journal; 9(2): 78-83.

Pintauli, S. dan Hamada, T. 2007. Menuju gigi dan mulut sehat. Pencegahan dan Pemeliharaan. Medan: USU Press: 1-20. 
Suwelo, S.S. 1992. Karies gigi pada anak dengan pelbagai faktor etiologi. Kajian pada anak usia prasekolah. Jakarta: EGC: 3-5.

World Health Organization. 1997. Oral health survey basic methods. 4th ed., Geneva.

World Health Organization. 2003. The World Oral Health Report. Geneva: 1-33.

Wright, G. 1998. Non-pharmacologic management of children behaviours. Dalam: Mc Donald et al., Dentistry for the Child and Adolescent. 8th ed., Mosby: 35-49. . 1992. Undang-Undang Nomor 23 tentang Kesehatan. Jakarta. 